\title{
Anatomical variations and pathological changes in the hearts of free-ranging Eurasian lynx (Lynx lynx) in Finland
}

\author{
Ilona Kareinen ${ }^{1} \cdot$ Emilia Lavonen $^{1} \cdot$ Suvi Viranta-Kovanen ${ }^{2} \cdot$ Katja Holmala $^{3}$ (D) Juha Laakkonen ${ }^{1}$
}

Received: 3 April 2019 /Revised: 1 December 2019 / Accepted: 14 December 2019 / Published online: 18 January 2020

(C) The Author(s) 2020

\begin{abstract}
The Eurasian lynx (Lynx lynx) despite the wide distribution has fragmented populations with possibly decreased genetic variability. Reports from Central Europe have raised cardiac health as possible risk factor for lynx populations. The knowledge on normal anatomic variations of lynx heart is crucial to assess emerging pathological or hereditary disorders. The aim of this study was to give a detailed description of the cardiac anatomy and circulation of the Eurasian lynx and to report the cardiac health of the lynx in Finland. The cardiac anatomy and pathology were studied post mortem from 63 legally hunted lynx. In general, the cardiac anatomy of Eurasian lynx corresponded with that described for other felids. In the ventricles, varying number of thin ventricular bands was a common feature and their histological appearance was characterized by a fibromuscular pattern. The size of the heart varied between males and females, but the relative size was similar to that described for most domesticated carnivores. No marked pathologic lesions were observed in the lynx hearts. Fibrosis was observed in 56\% of the hearts, but it was focal and mild in degree and unlikely to affect cardiac function or to have clinical significance. In conclusion, the cardiac health of the Finnish Eurasian lynx population is good with no signs of heritable cardiac disorders. Furthermore, we were able to give a detailed anatomic description of the lynx heart, which can serve as a reference for further epidemiological investigations on cardiac diseases in lynx populations.
\end{abstract}

Keywords Anatomy $\cdot$ Cardiac health $\cdot$ Eurasian lynx $\cdot$ Heart $\cdot$ Lynx lynx $\cdot$ Population health

\section{Introduction}

The health of the apex predators reflects the overall health of any wildlife ecosystem with a key role in wildlife disease regulation and in biodiversity maintenance (Stier et al. 2016). In many terrestrial ecosystems, wild Felidae are important apex predators. Yet, the constantly changing environment, climate change and competition with human population for

Ilona Kareinen and Emilia Lavonen contributed equally to this work.

Katja Holmala

katja.holmala@luke.fi

1 Department of Veterinary Biosciences, Faculty of Veterinary Medicine, University of Helsinki, PO Box 66, FI-00014 Helsinki, Finland

2 Department of Anatomy, Faculty of Medicine, University of Helsinki, PO Box 63, FI-00014 Helsinki, Finland

3 Natural Resources Institute Finland (Luke), Latokartanonkaari 9, FI-00790 Helsinki, Finland valuable food resources place these enigmatic species at risk. The attitudes towards apex predators among people are often contradictory, and decisions on conservation and hunting are often reflected by emotions ranging from spite and fear to admiration (Yodzis 2001).

The Eurasian lynx (Lynx lynx) has a wide distribution area in Eurasia, but many of the European populations are highly fragmented and the sub-populations small. This may lead to narrowing of the genetic variability in the population and increased inbreeding. A known example of reduced viability in the Felidae family caused by these factors is the Florida panther (Puma concolor coryi), which suffers from skeletal, reproductive and congenital abnormalities (Roelke et al. 1993). On species level, the health of the Eurasian lynx is considered to be relatively good. The main causes of mortality for adult lynx in Scandinavia are related to anthropogenic activities such as vehicular collisions, pouching and hunting, with starvation, intra- and interspecies killing and disease only having a minor role (Andrén et al. 2006). Endo- and ecto-parasitic infections are common in Eurasian lynx populations, but the parasitic infections are rarely lethal or cause a clinical disease 
(Jokelainen et al. 2013; Kołodziej-Sobocińska et al. 2018). However, scientists from other parts of Europe have reported cardiovascular changes, especially from re-introduced subpopulations of the free ranging lynx, such as subaortic stenosis, arteriosclerosis and myocardial fibrosis, and surmise them as possible health hazards for the species (Ryser-Degiorgis et al. 2004; Ryser-Degiorgis and Robert 2006). These pathologic lesions are more frequent and severe in Swiss lynx populations, where the sub-populations are small and isolated, compared with the larger and seemingly healthier Swedish lynx populations (Ryser-Degiorgis and Robert 2006). It has been speculated that captured Eurasian lynx could be predisposed to cardiomyopathies due to the high level of inbreeding (Heaver and Waters 2019). In the zoos of United Kingdom, circulatory diseases, neoplasia, suspected idiopathic epilepsy and renal diseases were reported to be the most common causes of death when excluding euthanizing animals as part of population management (Heaver and Waters 2019). Where circulatory diseases were reported as the cause of death, cardiomyopathy was the main finding in three, with two cases of arteriosclerosis and one case of myocardial fibrosis. To our knowledge, the anatomy of the lynx heart has not been described in the literature in detail before. Rowlatt (1990), however, provides a general description for the felid hearts. According to her, both the pantherine and feline hearts are round in shape with the left ventricle forming the apex. In the ventricles, the papillary muscles are short and the walls contain heavy trabeculae carneae muscle, with only a small membranous part present.

Due to restricted hunting, by the beginning of this century, the lynx population in Finland had been able to increase and recolonize the areas where it had been previously eradicated. The current population, having approximately 2000 individuals, is distributed fairly evenly in Finland, with lower densities in the north (Holmala et al. 2019). Although lynx is a strictly protected species (under the EU Habitats Directive), the Finnish Ministry of Agriculture and Forestry allocates a yearly hunting quota for the Eurasian lynx. Several hundred individuals are thus legally hunted each year. This provides an excellent opportunity to collect post mortem health data from these animals.

In this study, we performed gross and microscopic examinations on lynx hearts obtained from the hunters. Since no single gross or microscopic lesion alone can fully predict the clinical relevance of a cardiac pathological finding, we performed a full macroscopic examination of the heart focusing on the different functional and anatomical structures of the heart in accordance with the general guidelines for postmortem cardiac examination (Robinson and Robinson 2015). In domestic cats, hypertrophic cardiomyopathy is the most common form of cardiomyopathy, and its most distinctive feature is the relative increase of cardiac weight (Kershaw et al. 2012). Furthermore, in cats, cardiac related unexpected death is relatively common (Wilkie et al. 2015), and, in these cats, histologically myofiber disarray, interstitial fibrosis, subendocardial fibrosis and intramural arteriolosclerosis are typical findings. Thus, the abovementioned features were closely evaluated in attempt to assess the cardiac health of the lynx. Our aim was to describe the cardiac anatomy of the lynx and to gather information on the anatomical variations and pathological changes occurring in lynx hearts in Finland.

\section{Materials and methods}

\section{Animals}

The carcasses of the Eurasian lynx (Lynx lynx) $(n=63)$ were from legal hunting during hunting seasons in 2013-2016 throughout the distribution area of lynx in Finland (Fig. 1). Two of the individuals were shot based on damage prevention licenses and one due to police issued order. The frozen carcasses were sent to the Taivalkoski research station of Natural Resources Institute of Finland, where various samples for morphological and health studies were taken by the technical laboratory assistants.

\section{Macroscopic examination of the heart}

In the autopsy done to monitor the biology of the lynx population, the sex and body weight of the lynx $(N=63)$ were determined. Ages of the individuals were determined from cementum annuli analysis of tooth samples by the Matson's Laboratory, Milltown, Montana USA. The animals were classified as young (age $<2$ years) or adults (age $>2$ years). The hearts, along with the pericardium, were excised two centimeters above the aortic valves (thus cutting off the major vessels associated with the heart) and stored frozen $\left(-20^{\circ} \mathrm{C}\right)$. Further, macroscopic and microscopic examinations were later performed by the authors of this study in the Faculty of Veterinary Medicine in Helsinki.

After thawing, the pericardial sac was removed from the hearts, and, if necessary, the hearts were rinsed in tap water to remove any remaining blood. All hearts were photographed, and the circumference of the heart was measured. If any significant length of aorta was left, it was measured from the base to the brachiocephalic trunk. The diameters of the aorta and pulmonal trunk were measured with a digitronic caliper (Moore \& Wright) approximately two centimeters above the arterial valves. After removal of these major blood vessels, the weight of heart was recorded with an Ohaus@LS200 portable balance (OHAUS Europe $\mathrm{GmbH}$, Switzerland). The atria were dissected open and the macroscopic anatomy determined. The left ventricle was cut open with scissors along the septum, and its length was measured from the atrioventricular border to the apex of the heart. The ventricle was studied 


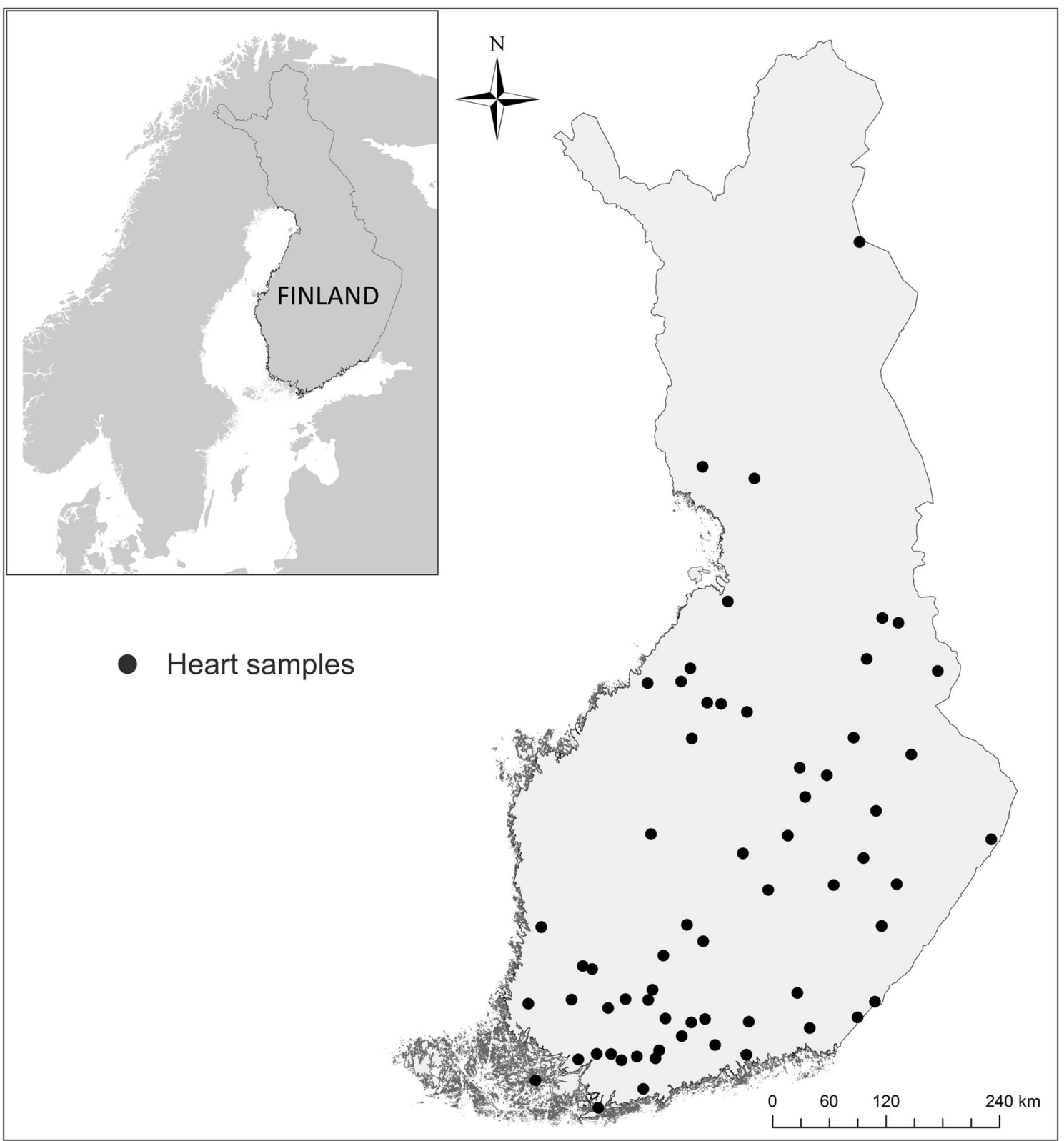

Fig. 1 Geographic locations of the Eurasian lynx heart samples $(N=63)$ from years 2013-2016 in Finland

for any abnormalities, and the number and location of ventricular bands (also named as false tendons or trabeculae tendineae in the literature) was recorded. The right ventricle was similarly dissected and studied. The thickness of both ventricular walls was measured with a ruler from the halfpoint of the longitudinal axis of the ventricle avoiding any papillary muscles (the long axis of the heart is parallel to the sternum).

For the visualization of the major coronary vessels, silicone casts were prepared from four heart specimens, as previously described (Laakkonen and Kivalo 2013). In brief, a twocomponent silicone (3 M Express $\odot 2$ Light Body Standard Quick) was injected using a gun-like silicone dispenser to apply the mix separately into aorta and coronary veins of the heart. Surgical clamps were used to prevent the silicone from flowing out of the vessels before the cast was set. After the silicone had hardened in 2-3 min in room temperature, the specimens were placed into a bucket of sodium hypochlorite solution (14\%, Sigma-Aldrich, Switzerland) in a horizontal position for removal of heart tissue. The finished casts were stored in room temperature and examined for branching of the major coronary vessels, as well as for the inside morphology of the walls of the atria and ventricles.

\section{Histologic examination of the heart}

For histological examination, samples $(1 \mathrm{~cm} \times 1 \mathrm{~cm})$ with epicardium, myocardium and endocardium were taken from the midsection of walls of both ventricles and from the septum 
between the ventricles. In addition, samples from the ventricular bands of the left ventricle were taken from eight hearts to determine their tissue composition. Samples from valva and cusps were taken if macroscopic abnormalities were observed. The tissue samples were fixed with $10 \%$ neutral buffered formalin, cut in 3-4- $\mu \mathrm{m}$-thick sections and stained using hematoxylin and eosin (H\&E) and Masson's trichome (MT) stains. The histologic sections were examined via light microscope and lesions were semi quantitatively scored by applying the criteria in Wilkie et al. (2015). Shortly, the histological sections were scored for cardiomyocyte hypertrophy, myofiber disarray, fibrosis, infiltration of inflammatory cells, arteriosclerosis, myocyte degeneration or necrosis and infiltration of adipocytes. MT stained sections were specifically examined for the presence of fibrosis and arteriosclerosis. Fibrosis was determined as interstitial, perivascular or replacement fibrosis. According to Wilkie et al. (2015), interstitial fibrosis was determined as strands of fibrous connective tissue surrounding myocytes where as more diffuse, confluent areas of fibrosis substituting myocytes were classified as replacement fibrosis. Fibrosis strictly surrounding blood vessels was specified as perivascular fibrosis. Furthermore, fibrosis was specified as simple fibrosis if only one type of fibrosis was present.

\section{Statistical methods}

Statistical analyses were performed using Microsoft Excel, SPSS statistical software for Windows and Graph Pad Prism (version 8.0.2). Statistical evaluations of differences between two groups were identified using the unpaired Student's $t$ test with Welch's correction for normally distributed data. For data sets with more than two groups, the Freeman-Halton extension of Fisher's exact test was used to assess statistical significance. Data are presented as means \pm standard deviations (SD). Statistical significance was set to $p<0.05$. Graphs were created using the Graph Pad Prism program.

\section{Results}

Our data included 30 females and 33 males. Approximately half of the lynx (48\%) were less than two years of age (Fig. 2). The males had significantly higher mean skinned body weights (mean $17.2 \mathrm{~kg}$; SD 5.1; range 7.8-25.5 kg) compared with females (mean $14.5 \mathrm{~kg}$; SD 2.3; range 7.9-19.2 kg) ( $p=$ $0.008)$. Both young males $(N=16)$ and females $(N=14)$ had significantly lower skinned body weights (mean $13.9 \mathrm{~kg}$; SD 5.1; range 7.8-25 kg and mean $13.4 \mathrm{~kg}$; SD 2.6; range; 7.9$16 \mathrm{~kg}$, respectively) compared with adult males $(N=17$; mean $20.4 \mathrm{~kg}$; SD 2.5; range 16-25.5 kg; $p=0.0001)$ and females $(N=16$; mean 15.48; SD 1.5; range 13.6-19.2 kg; $p=0.016)$. Accordingly, sex differences were also observed in the size of the heart. The morphometric measurements of the hearts are

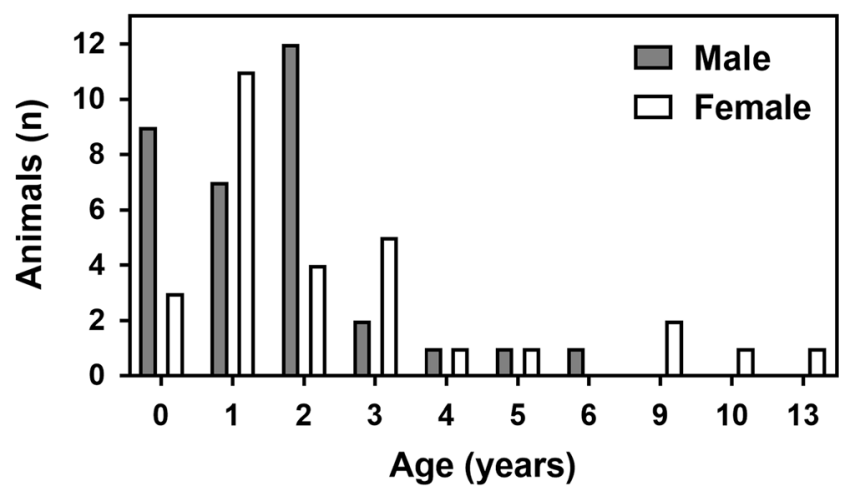

Fig. 2 The sex and age distribution of the lynx (males, $n=33$; females $n=30$ ). The age of one individual was not known

presented in Table 1 . The hearts of the males were significantly larger than those of the females $(p=0.036)$. There were no other statistically different cardiac parameters between male and female lynx (Table 1). The weight of the heart constituted $0.41 \%$ of the body weight in males $(\mathrm{SD}=0.057)$ and $0.44 \%$ in females $(\mathrm{SD}=0.050)$, and it had strong correlation with the body weight (correlation coefficient $0.85, p=0.01$; Fig. 3 ). The heart weight to body weight (HW:BW) ratio was slightly higher both in young males $(0.42 \% ; \mathrm{SD}=0.112)$ and females $(0.45 \%$; SD 0.038$)$ compared with adult males $(0.4 \%$; $\mathrm{SD}=$ $0.054)$ and females $(0.43 \%$; $\mathrm{SD}=0.058)$, but the difference was not statistically significant.

\section{Gross anatomy of the lynx heart}

Most dissected hearts included the pericardium, with at least moderate amounts of pericardial fat. Additionally, epicardially deposited fat was present in the left auricle in $71 \%$ of the hearts and in $3 \%$ of the hearts also in the right auricle. The heart of the lynx was ovoid-shaped but a few hearts had an almost round appearance. On the cranial side, the pulmonary trunk was located cranial to the aorta. Both the aorta and the pulmonary trunk had the typical valve apparatus composed of three crescent-shaped cusps each. The pulmonary veins had been partly or entirely cut off before the hearts were examined for this study. The general anatomical appearance of the lynx heart is shown in Fig. 4a.

\section{The atria}

The endocardial surface of the left atrium was smooth except for the distinct pectinate muscles on the left auricle. The walls of the right atrium were very thin, and pectinate muscle was present only in the right auricle. The oval fossa was visible in the interatrial septum as a shallow depression. The diameter of the coronary sinus ranged from two to three millimeters. 
Table 1 Macroscopic measurements of the Eurasian lynx heart. The statistical evaluations between the male and female parameters were identified using the Student's $t$ test. * $=$ $p<0.05 . \varnothing$, diameter

\begin{tabular}{|c|c|c|c|c|c|c|}
\hline & \multicolumn{2}{|l|}{ Males } & \multicolumn{2}{|l|}{ Females } & \multicolumn{2}{|c|}{ Number } \\
\hline & Mean (SD) & Range & Mean (SD) & Range & Males & Females \\
\hline Weight of the heart $(\mathrm{g})^{*}$ & $70.7(17.5)$ & $38.3-100.5$ & $62.9(10.6)$ & $39.3-78.8$ & 33 & 30 \\
\hline Circumference (cm) & $13.8(1.3)$ & $10.9-15.7$ & $13.4(1.1)$ & $10.9-15.2$ & 31 & 29 \\
\hline Length of the left ventricle $(\mathrm{cm})$ & $4.9(0.6)$ & $3.5-6.1$ & $5.0(0.5)$ & $3.9-6.1$ & 33 & 30 \\
\hline Left ventricle $\varnothing(\mathrm{mm})$ & $11.1(2.3)$ & $7.4-17$ & $10.4(1.3)$ & $7.0-13.0$ & 33 & 30 \\
\hline Right ventricle $\varnothing$ (mm) & $2.8(1.0)$ & $1.2-5.9$ & $3.0(1.9)$ & $1.2-12$ & 33 & 30 \\
\hline Aorta $\varnothing(\mathrm{mm})$ & $9.7(1.1)$ & $8.0-12.5$ & $9.0(1.0)$ & $7.0-11.0$ & 33 & 30 \\
\hline Truncus pulmonalis $\varnothing$ (mm) & $10.3(1.4)$ & $6.0-13.0$ & $9.7(0.8)$ & $8.0-11.0$ & 32 & 28 \\
\hline
\end{tabular}

\section{The ventricles}

The left and right ventricles of the lynx contained numerous, longitudinally directed trabeculae carneae (Fig. 4b). The septomarginal trabecula extended from interventricular septum to the opposite wall and were frequently plural and branched.

\section{The right ventricle}

The papillary magnus muscle, the largest papillary muscle of the right chamber was related to the free wall. The papillary parvi muscles were situated caudally on the septal wall. The papillary subarterious muscle was situated on the septal wall, medially to the other papillary muscles, and ventral to the opening of the pulmonary trunk.

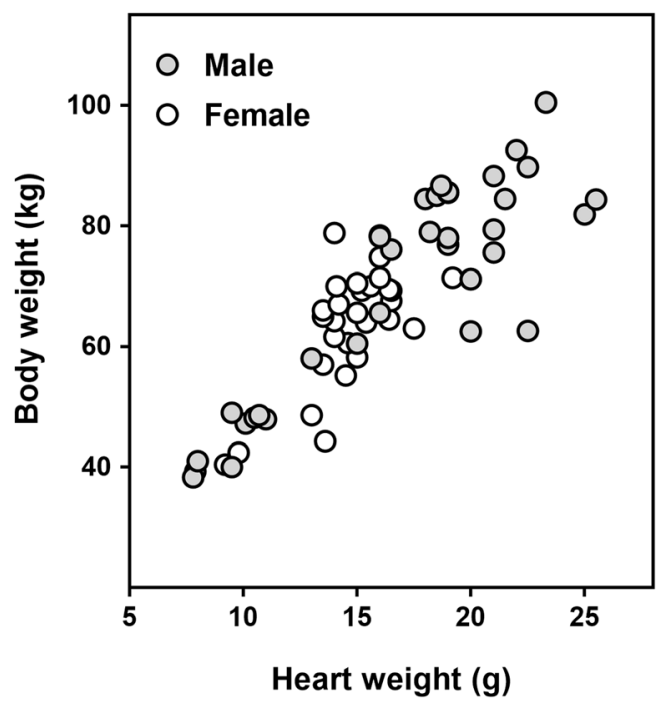

Fig. 3 The ratio between heart and body weight of the male and female lynx (males, $n=33$; females $n=30$ ). The weight of the heart correlates strongly with the body weight (correlation coefficient $0.85, p=0.01$ )

\section{Left ventricle}

The papillaris subauricularis muscle was located on the parietal wall caudal to the left auricle and the papillaris subatrialis muscle on the septal wall, caudal to the left atrium. The two papillary muscles were distinct and covered a relatively narrow area of the ventricular wall. As a result the chorda tendinae were tightly grouped making the atrioventricular valves more easily distinguishable than the tricuspidal valves.

Besides the chorda tendinae, thin ventricular bands from the papillary muscles to the ventricular walls were visible in both ventricles but they were a much more common finding in the left (in $71 \%$ of the hearts) than in the right (18\%) ventricle. The ventricular bands were also more numerous in the left ventricle. The diameter of the bands varied only minimally and was generally one millimeter or less. The bands were single or multiple, and frequently branched from two or three sites of attachment (Fig. 4b). In some hearts, the bands were slightly thicker and were found in couples or triplets, while in other hearts there were many small, thin bands, which formed net-like structures. Most commonly, one or two longer bands were located in the middle part of the ventricle traversing the ventricular cavity from the interventricular septum to the ventricular free wall or papillary muscles, or multiple short bands were situated in the lower part of the ventricle. All ventricular bands from the left ventricle examined histologically consisted of myocytes surrounded by thick bands of connective tissue with a superficial endothelial lining (Fig. 5).

\section{Coronary circulation}

The coronary orifices were located in the two sinuses of the aortic valve (the left and right coronary sinuses). In ten lynx, there were accessory coronary orifices. The accessory orifices occurred more commonly on the left side (7/10) of the coronary orifice. Additionally, in two lynx, the coronary orifice originated as one large orifice, which immediately divided into two smaller orifices. 
Fig. 4 General anatomical appearance of the lynx heart. Typical ovoid shaped lynx heart (a). Lynx heart with left ventricle opened (b) showing the trabeculae carneae (arrowhead) and chorda tendinae (asterix) of the left ventricle. A few thin ventricular bands (arrow) are also present. LA left atrium, LV left ventricle, LVW left ventricular wall, MV mitral valve, RVW right ventricular wall

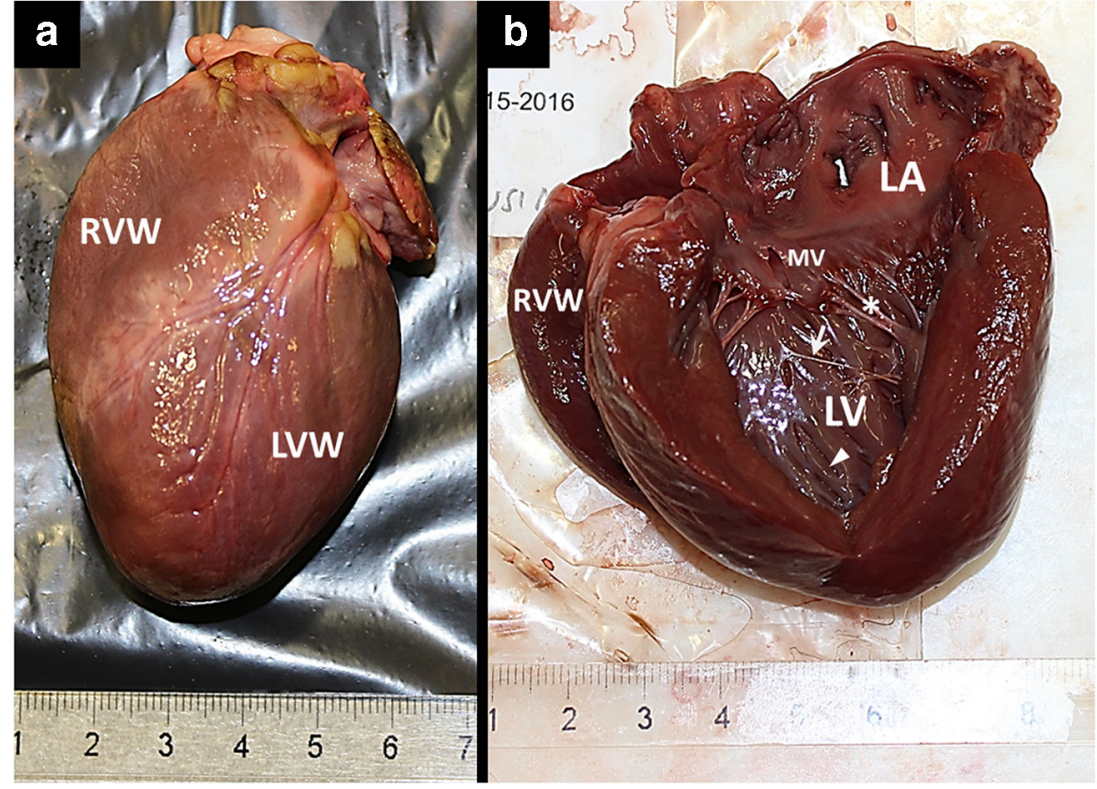

The main coronary arteries were clearly visible in all four silicone models (Fig. 6), but the smaller arteries and the coronary veins were difficult to reproduce. This was most likely caused by the freezing and thawing of the specimens, and, in the case of veins, the flow of silicone might also restricted by the valves. Additionally, the lack of pulmonary veins, which were cut off near the base of the heart, made it challenging to keep the silicone flowing into the veins. The slightly larger left coronary artery arose in the sinus of the caudosinistral valve, and after forming a short trunk divided into four branches. The largest of these, the interventricularis paraconalis decendens branch divided immediately into a one larger branch and three smaller branches (Fig. 6), and ran into the interventricularis paraconalis sulcus before branching into three larger rami. Of the other branches originating from the main trunk, the circumflex branch continued caudally branching into numerous small rami. Opposite the circumflex branch, a similar size septal branch turned right into the interventricular septum. The right coronary artery arose above the right semilunar cusp and followed the coronary sulcus dividing into numerous rami of different sizes before descending as the interventricular subsinosus branch towards the apex of the heart.

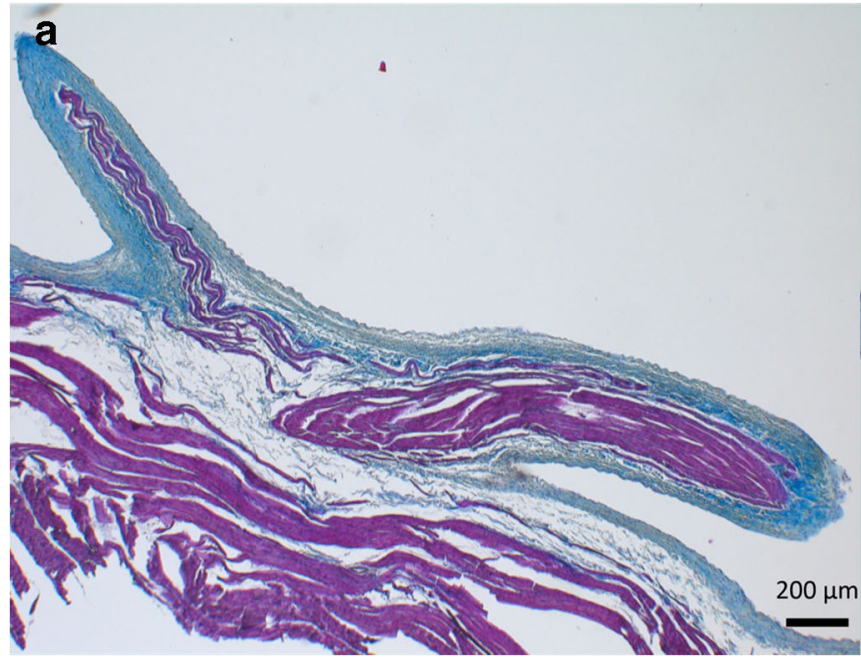

Fig. 5 Representative micrographs of ventricular bands. Two ventricular bands projecting from the left ventricular wall (a), 50× magnification. A cross section of a ventricular band of the left ventricle (b). Myocytes (purple) are surrounded by thick crisscrossing bands of connective tissue b

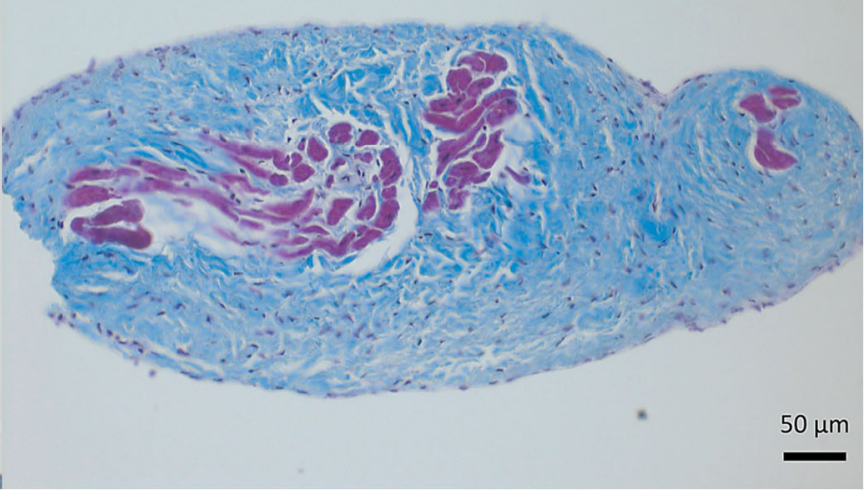

(blue). An undulating monolayer lining of endothelial cells surrounds the ventricular band. The cellularity of the connective tissue is low and consists of scattered elongated, spindle-like fibroblasts. $200 \times$ magnification. Masson's trichome stain 


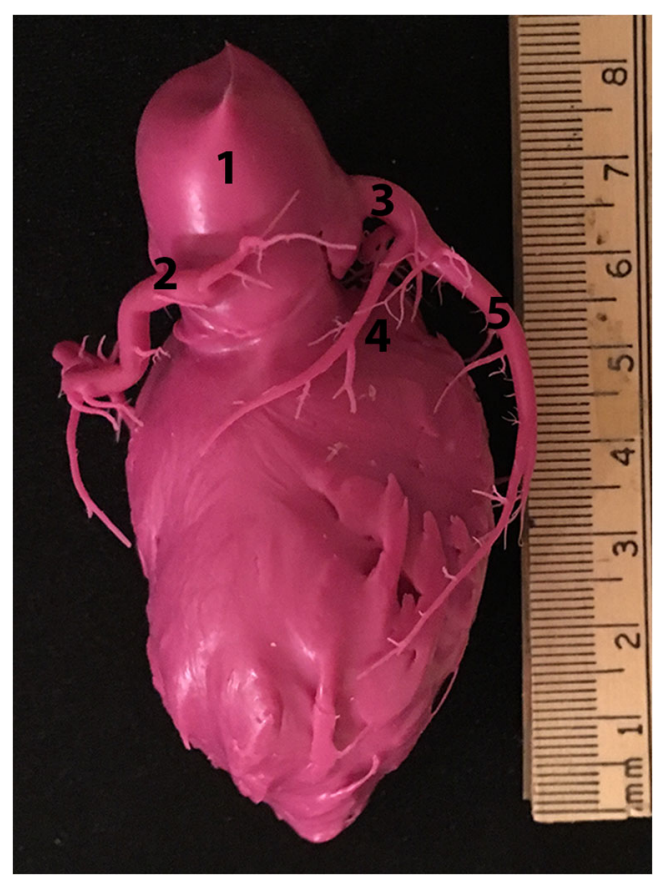

Fig. 6 Silicone cast of the heart of a young female lynx. $1=$ aorta, $2=$ right coronary artery, $3=$ left coronary artery, $4=$ septal branch, $5=$ paraconal interventricular branch

\section{Macroscopic and histopathological findings of the lynx hearts}

There were no marked macroscopic pathologic findings in the studied hearts. Thin ventricular bands were observed in the majority of hearts, as described above, but they were considered a normal anatomic variation since they were not associated with histologic lesions consistent with previous inflammation or other pathologic conditions. Oval foramen was closed in all hearts but could not be evaluated in one heart due to damage caused by the gunshot wound. The atrioventricular and arterial valves appeared normal in gross examination with a smooth and even surface in all but one heart. In that heart, the mitral valve had focal, mild, nodular, smooth thickening that was glistening on the surface. Histologically, the lesion consisted of a moderate, focal thickening of lamina spongiosa with mild proliferation of fibroblasts, accumulation of myxomatotic material and isolated intralesional lymphocytes, plasma cells and macrophages.

On histologic examination, fibrosis was observed in $56 \%$ of the hearts $(N=34)$. Fibrosis was classified as interstitial, perivascular or replacement fibrosis and was specified as simple fibrosis if only one type of fibrosis was present. A typical presentation of perivascular and replacement fibrosis is shown in Fig. $7 \mathrm{a}$ and $\mathrm{b}$. The most common fibrosis type was the interstitial fibrosis, either alone or together with perivascular or replacement fibrosis (Table 2). In most hearts, only one type of fibrosis was present (simple fibrosis; $35 \%$ of hearts). However, in $14 \%$ of the hearts, two types of fibrosis, presented in detail in Table 2 , and in
$7 \%$ all fibrosis types were present. Fibrosis was focal and of minimal to mild in degree in all of the hearts. Most commonly, fibrosis was present in the right ventricle $(N=23 ; 38 \%)$, followed by the left ventricle $(N=15 ; 25 \%)$ and septum $(N=9 ; 15 \%)$. The difference in the occurrence of lesions between the cardiac compartments was statistically significant $(p=0.02)$. Neither the degree nor the presence of fibrosis was associated with the size of the heart or the age of the lynx. Furthermore, fibrosis was not associated with infiltration of inflammatory cells or with other lesions consistent with previous inflammation, parasites or circulatory disorders. Few isolated mononuclear inflammatory cells were observed scattered between the myocardial fibers in all of the studied hearts (Fig. 7c). In 13\% of the hearts a focal, minimal to mild infiltration of lymphocytes or plasma cells was observed (Fig. 7d). The focal lympho-plasmacytic cell infiltrate accounted for $1-5 \%$ of the nucleated cells of the examined high power field. In addition to fibrosis and inflammatory cell infiltrates, the hearts were also examined for morphological features for cardiomyocyte hypertrophy (plumb myocytes with large vesicular nuclei), myofiber disarray (inter-weaving or crisscrossing myofibers), arteriosclerosis, myocyte degeneration and infiltration of adipocytes. These pathologic lesions were not observed in any of the studied lynx hearts.

\section{Discussion}

The fact that, hearts of the males were significantly larger than those of the females is directly linked to the body size difference, which is due to observed sexual dimorphism also in the body size. In general, male lynx are about $30 \%$ larger than adult females (Kojala and Holmala 2009). The relative size of the lynx heart, measured as the HW:BW ratio, falls in the same range as the heart of the domestic cat Felis catus (Robinson and Robinson 2015). There was no significant difference between sexes or age groups in HW:BW ratio in male and female lynx contrary to previous observations reporting that in most mammals the HW:BW ratio is greater in males than in females of the same species (Robinson and Robinson 2015).

The gross anatomy of lynx heart was similar to that described for domestic cat (Nickel et al. 1981) and tiger Panthera tigris (Perez and Lima 2007). Apart from the anatomical variation in the number of ventricular bands and coronary orifices, no gross anatomical variations possibly affecting the function of the heart, were observed in any of the studied lynx. We found no persistent foramen ovale. In contrast, the condition is frequently seen in humans. The occurrence of the persistent foramen ovale in humans and other mammals has recently been discussed by Jensen et al. (2019).

Ventricular bands are thin, fibrous or fibromuscular bands that traverse the cavity of the left side and ventricles in humans and many other mammals (Kervancioğlu et al. 2003; Deniz et al. 2004; Philip et al. 2011; Cope 2017). Kimura et al. (2016) 


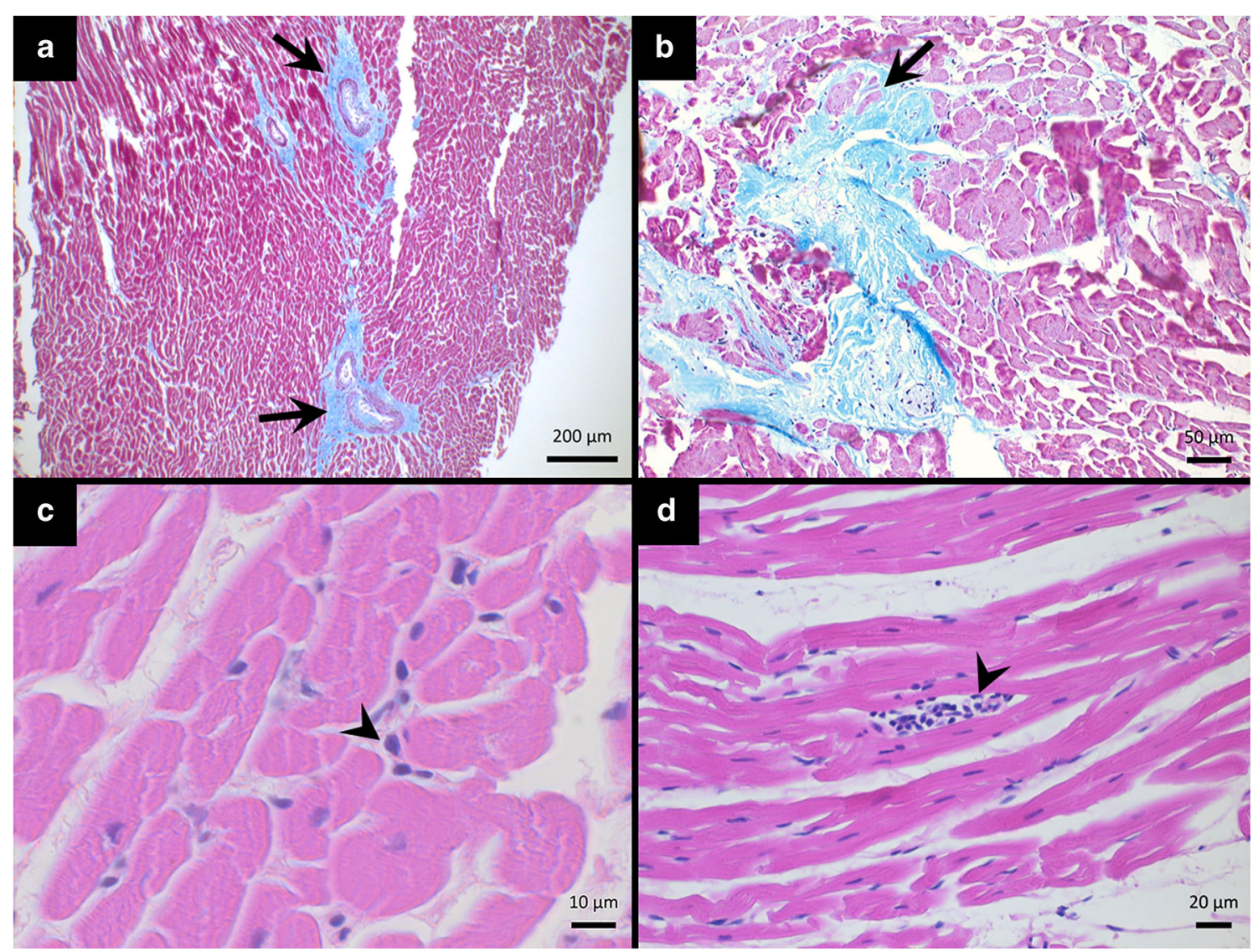

Fig. 7 Representative micrographs of histological findings in the lynx hearts. Mild perivascular fibrosis (arrows) surrounding small cardiac arteries (a). Fibrosis is restricted to the perivascular area and only short, thin bands of MT positive (blue) fibrous strands extend from perivascular area and surround isolated myofibers. Focally extensive area of replacement fibrosis (b). Fibrosis (blue) has substituted myofiber tissue (purple) and

reported that in the domestic cats, these bands were not simple connective tissue fibers but were instead composed of central Purkinje fibers surrounded by dense collagen bundles, with

Table 2 Types of fibrosis in the studied lynx hearts $(N=63)$. Fibrosis was classified as interstitial, perivascular or replacement fibrosis. Fibrosis was specified as simple fibrosis if only one type of fibrosis was present

\begin{tabular}{lcc}
\hline Type of fibrosis & Number (\%) \\
\hline No fibrosis & 26 & $(43)$ \\
Simple fibrosis & & \\
$\quad$ Interstitial fibrosis & 13 & $(22)$ \\
$\quad$ Perivascular fibrosis & 6 & $(10)$ \\
$\quad$ Replacement fibrosis & 2 & $(3)$ \\
Two fibrosis types & & \\
$\quad$ Interstitial and perivascular fibrosis & 5 & $(8)$ \\
$\quad$ Interstitial and replacement fibrosis & 2 & $(3)$ \\
$\quad$ Perivascular and replacement fibrosis & 2 & $(3)$ \\
All fibrosis types & 4 & $(7)$ \\
\hline
\end{tabular}

an island of normal appearing myocytes (arrow) is left isolated in the midst of fibrous tissue. Isolated lymphocytes (arrowhead) between myofibers (c). Focal lymhoplasmacytic infiltrate (arrowhead) between myocyte fibers (d). No additional morphological features of inflammation are observed in the near vicinity of inflammatory infiltrate. (a) and (b) Masson's trichome (MT) stain, (c) and (d) H\&E stain occasional proliferations of fibroblasts and/or smooth muscle cells and a superficial endothelium, suggesting that interspecies differences in the tissue composition of ventricular bands would occur. All ventricular bands examined histologically in this study consisted of a fibromuscular tissue. This anatomic arrangement was especially prominent in tissue sections representing the attachment of ventricular bands to the endocardium (Fig. 5). The ventricular bands had no connection to the cusps of the valves. Most of the publications on ventricular bands focus on the left ventricle, possible because there the bands are larger and more visible (Kosiński et al. 2012). However, these bands are commonly found in right ventricle of the domestic dogs, where they typically extend from the interventricular septum to the ventricular free wall (Cope 2017). These fibrous bands are a frequent finding in left ventricle of cats, where they extend between the papillary muscles and the ventricular septum (Gerlis et al. 1984; Kimura et al. 2016). The incidence, morphology and distribution of the bands were equal both in the healthy and diseased hearts indicating that the bands are a normal anatomic variant of the domestic cat heart (Kimura 
et al. 2016). However, excessive diffuse networks of ventricular bands have been associated with heart failure and death in cats (Liu et al. 1982; Robinson and Robinson 2015).

The presence of accessory coronary orifices has been reported in other mammalian species, including the domestic, shorthair cat (Barszcz et al. 2016) and the Syrian hamster (Durán et al. 2007). They are also a known entity in humans but having only little clinical significance (Angelini 1989). In our study, the proportion of lynx with an accessory coronary orifice or other variation of its formation was similar to that of domestic cats, $19 \%$ and 20\%, respectively (Barszcz et al. 2016). In domestic cats, additional ostia were most commonly found in conjunction with the right coronary ostia, whereas in the present study they were located in the left. The differences in the locations of the coronary orifices or the presence of additional orifice in other mammalian species and the possible effect on the coronary circulation have been discussed extensively by Barszcz et al. (2016).

Previous research in the domestic dogs and cats (Barszcz et al. 2014) indicates that the main trunk of the left coronary artery is in most cases wider than the trunk of the right coronary artery. Also, in our study, all the lynx with elevated coronary tree $(N=4)$, the left coronary artery was wider than the corresponding right one. Barszcz et al. (2014) have shown intraspecific variation in the main branches of the common trunk of the left coronary artery. In the lynx, there was only minor variation in the branching of the paraconal interventricularis artery, even less than that of the domestic cat and tiger (Perez and Lima 2007; Barszcz et al. 2014). Variation in the branching patterns of the left coronary artery in the domestic dogs has also been reported (Noestelthaller et al. 2007). The right coronary artery of the lynx continued as a interventricular subsinosus branch as described for the domestic cats (Barszcz et al. 2014) and in the lynx, the coronary circulation was balanced similar to that of cougar Puma concolor (Viotto-Souza et al. 2017). Dominance of left coronary (i.e. the interventricular subsinosus branch being a branch of the circumflex artery) has been reported in the wild cats Felis silvestris, in one lion Panthera leo and one tiger (Hadziselimovic et al. 1974; Perez and Lima 2007; Borelli 2014; Barszcz et al., 2014).

In cats, the great cardiac vein and the middle cardiac vein open into the coronary sinus, and the coronary sinus is a continuation of the great cardiac vein (Nickel et al. 1981; Aksoy et al. 2001). Although the coronary veins were not properly reproduced in silicone casts, observations made during dissection of lynx hearts indicated that the main branching of coronary veins was similar to that described for the domestic cats.

Based on the microscopic and macroscopic examination, the cardiac health of the Finnish lynx was good with no significant pathological lesions. Approximately half of the lynx were young, under two years of age, which may result in some underestimation on the occurrence of pathological changes occurring with advancing age. The absence of severe pathologic changes was not surprising since such findings would be unlikely in a growing and vital population such as the Finnish lynx. The most common finding was minimal to mild focal fibrosis, observed in $56 \%$ of the hearts in some compartment. Fibrosis was not associated with lesions consistent with inflammation, parasites, circulatory disorders or typical congenital abnormalities, and thus it cannot be ruled out, if such mild degree of fibrosis could be within normal physiological variation or simply a marker of a previous, already healed inflammation/infection. Ryser-Degiorgis and Robert (2006) describe in a Swiss lynx population an increased incidence of myocardial fibrosis characterized by varying degree of perivascular or interstitial fibrosis with random distribution. In their report, however, the incidence of arteriosclerosis and fibrosis were combined resulting in $65.8 \%$ of hearts being affected by either condition. They also reported a combined incidence of $23.8 \%$ of arteriosclerosis and fibrosis in a Swedish lynx population. The overall incidence of fibrosis in the Finnish lynx population falls somewhere between the values reported in the Swedish and Swiss lynx populations but comparison between these studies is difficult due to the combined incidences of arteriosclerosis and fibrosis and lack of reference values or more detailed descriptions or limiting values for fibrosis.

Some studies in Central Europe have linked certain cardiac pathologic changes in lynx to inbreeding (Ryser-Degiorgis and Robert 2006). In our study, no marked macroscopic or microscopic cardiac lesions consistent with congenital or hereditary anomalies were observed. Furthermore, a recent study on lynx genetics in Finland (Holmala et al. 2018) confirmed that inbreeding is not of concern in the Finnish lynx population further demonstrating the good viability of the lynx population in Finland.

Acknowledgments We thank Karolina Barszcz for providing us translations of key parts of her papers on coronary vessels of cats, Tuire Pankasalo and Marja Peltola for technical assistance, laboratory technicians of the Taivalkoski research station for the sample collection and voluntary hunters for providing the samples.

Funding information Open access funding provided by Natural Resources Institute Finland (LUKE). This study was partly funded by the University of Helsinki (JL).

\section{Compliance with ethical standards}

Conflict of interest The authors declare that they have no conflicts of interest.

This article does not contain any studies with human participants or animals performed by any of the authors.

Open Access This article is licensed under a Creative Commons Attribution 4.0 International License, which permits use, sharing, adaptation, distribution and reproduction in any medium or format, as long as you give appropriate credit to the original author(s) and the source, 
provide a link to the Creative Commons licence, and indicate if changes were made. The images or other third party material in this article are included in the article's Creative Commons licence, unless indicated otherwise in a credit line to the material. If material is not included in the article's Creative Commons licence and your intended use is not permitted by statutory regulation or exceeds the permitted use, you will need to obtain permission directly from the copyright holder. To view a copy of this licence, visit http://creativecommons.org/licenses/by/4.0/.

\section{References}

Aksoy G, Karadag H, Soyguder Z et al (2001) A macroanatomic investigation on the cardiac vein in the domestic cat. J Health Sci Univ Firat 15:315-324

Andrén H, Linnell JDC, Liberg O et al (2006) Survival rates and causes of mortality in Eurasian lynx (Lynx lynx) in multi-use landscapes. Biol Conserv 131:23-32. https://doi.org/10.1016/J.BIOCON.2006.01.025

Angelini P (1989) Normal and anomalous coronary arteries: definition and classification. Am Heart J 117:418-435

Barszcz K, Kupczyńska M, Klećkowska-Nawrot J et al (2014) Arterial coronary circulation in cats (Felis silvestris f. catus). Med Weter 70:373-377

Barszcz K, Kupczyńska M, Klećkowska-Nawrot J et al (2016) Morphology of coronary ostia in domestic shorthair cat. Anat Histol Embryol 45:81-87. https://doi.org/10.1111/ahe.12174

Borelli V (2014) Contribuicao ao estudo da vascularizacao arterial do coracao de gatos (Felis domestica - Linnaeus 1758). J Health SciInst 32:299-303

Cope LA (2017) Morphology and classification of right ventricular bands in the domestic dog (Canis familiaris). Anat Histol Embryol 46:464 473. https://doi.org/10.1111/ahe.12291

Deniz M, Kilinic M, Hatipoglu ES (2004) Morphologic study of left ventricular bands. Surg Radiol Anat 26:230-234. https://doi.org/ 10.1007/s00276-003-0212-0

Durán A, Arqué JM, Fernández B, Fernández MC, Fernández-Gallego T, Sans-Coma V (2007) Separate origin of the main components of the left coronary artery in Syrian hamsters (Mesocricetus auratus). J Vet Med A 54:297-301

Gerlis LM, Wright HM, Wilson N, Erzengin F, Dickinson DF (1984) Left ventricular bands. A normal anatomical feature. Br Heart J 52:641647. https://doi.org/10.1136/hrt.52.6.641

Hadziselimovic H, Secerov D, Gmaz-Nikulin E (1974) Comparative anatomical investigations on coronary arteries in wild and domestic animals. Acta Anat 90:16-35

Heaver J, Waters M (2019) A retrospective study of mortality in Eurasian lynx (Lynx lynx) in UK zoos. Zoo Biol 38:200-208

Holmala K, Herrero A, Kopatz A, Schregel J, Eiken HG, Hagen SB (2018) Genetic evidence of female kin clusters in a continuous population of a solitary carnivore, the Eurasian lynx. Ecol Evol 8: 10964-10975. https://doi.org/10.1002/ece3.4562

Holmala, K., Mäntyniemi, S. \& Heikkinen, J. 2019. Ilveskanta Suomessa 2019. [Lynx population in Finland 2019, in finnish] Luonnonvaraja biotalouden tutkimus 47/2019. Luonnonvarakeskus. Helsinki. 32 s. Available at: https://riistahavainnot.fi/suurpedot/ suurpetotutkimus/wp-content/uploads/sites/4/2019/08/luke-luobio 47_2019.pdf. Accessed 14 June 2019

Jensen B, Wang T, Moorman AFM (2019) Evolution and development of the atrial septum. Anat Rec 302:32-48

Jokelainen P, Deksne G, Holmala K, Näreaho A, Laakkonen J, Kojola I, Sukura A (2013) Free-ranging Eurasian lynx (Lynx lynx) as host of toxoplasma gondii in Finland. J Wildl Dis 49:527-534. https://doi. org/10.7589/2011-12-352
Kervancioğlu M, Ozbăg D, Kervancioğlu P et al (2003) Echocardiographic and morphologic examination of left ventricular false tendons in human and animal hearts. Clin Anat 16:389-395. https://doi.org/10.1002/ca.10152

Kershaw O, Heblinski N, Lotz F (2012). Diagnostic value of morphometry in feline hypertrophic cardiomyopathy. J Comp Pathol 147:7383

Kimura Y, Karakama S, Kobayashi M et al (2016) Incidence, distribution and morphology of left ventricular false tendons in cat hearts. Anat Histol Embryol 45:490-493. https://doi.org/10.1111/ahe.12216

Kojala I, Holmala K (2009) Pienet hirvieläimet ja jänis saaliseläinyhteisön merkitys ilveksen kuntoon (Engl. The role of small ungulates for the physiological condition of lynxes in Finland). Suom Riista 55:63-70

Kołodziej-Sobocińska M, Yakovlev Y, Schmidt K, Hurníková Z, Ruczyńska I, Bednarski M, Tokarska M (2018) Update of the helminth fauna in Eurasian lynx (Lynx lynx) in Poland. Parasitol Res 117:2613-2621. https://doi.org/10.1007/s00436-018-5953-0

Kosiński A, Grzybiak M, Dubaniewicz A, Kędziora K, Makarewicz W, Kozłowski D (2012) False chordae tendineae in right ventricle of adult human hearts - morphological aspects. Arch Med Sci 5:834 840. https://doi.org/10.5114/aoms.2012.31617

Laakkonen J, Kivalo M (2013) The use of silicone casts in collection of morphological data from free-ranging wildlife - the case of tracheobronchial anatomy of the Eurasian Lynx ( Lynx lynx ). Ann Zool Fenn 50:256-261. https://doi.org/10.5735/085.050.0501

Liu S, Fox PR, Tilley LP (1982) Excessive moderator bands in the left ventricle of 21 cats. J Am Vet Med Assoc 180:1215-1219

Nickel R, Schummer A, Seiferle E (1981) The anatomy of domestic animals. The circulatory system, the skin, and the cutaneous organs of the domestic mammals. Volume 3. Paul Parey, Verlag, Berlin

Noestelthaller A, Probst A, König HE (2007) Branching patterns of the left main coronary artery in the dog demonstrated by the use of corrosion casting technique. Anat Histol Embryol 36:33-37. https://doi.org/10.1111/j.1439-0264.2006.00711.x

Perez W, Lima M (2007) Brief description of the cardiac anatomy in a tiger (Panthera tigris, Linnaeus, 1758): a case report. Vet Med (Praha) 52:83-86. https://doi.org/10.17221/2054-VETMED

Philip S, Cherian KM, Wu M-H, Lue H-C (2011) Left ventricular false tendons: echocardiographic, morphologic, and histopathologic studies and review of the literature. Pediatr Neonatol 52:279-286. https://doi.org/10.1016/j.pedneo.2011.06.007

Robinson WF, Robinson NA (2015) Chapter 1 - cardiovascular system. In: Maxie MG (ed) Pathology of domestic animals. Volume 3, 6th edn, pp 1-101

Roelke ME, Martenson JS, O'Brien SJ (1993) The consequences of demographic reduction and genetic depletion in the endangered Florida panther. Curr Biol 3:340-350. https://doi.org/10.1016/ 0960-9822(93)90197-v

Rowlatt U (1990) Comparative anatomy of the heart of mammals. Zoological Journal of the Linnean Society 98:73-110

Ryser-Degiorgis MP, Robert N (2006) Causes of mortality and diseases in free-ranging Eurasian lynx from Switzerland - an update. In: Proceedings of the "Iberian Lynx ex-situ conservation" seminar series, Module I, Veterinary Aspects, Sevilla. pp 31-35

Ryser-Degiorgis MP, Obexer-Ruf G, Breitenmoser U et al (2004) Emergence of congenital malformati ons in free-ranging Lynx from Switzerland: first evidence of inbreeding depression? European Association of Zoo- and Wildlife Veterinarians, pp 307-311

Stier AC, Samhouri JF, Novak M, Marshall KN, Ward EJ, Holt RD, Levin PS (2016) Ecosystem context and historical contingency in apex predator recoveries. Sci Adv 2:e1501769. https://doi.org/10. 1126/sciadv.1501769 
Viotto-Souza W, de Souza Junior P, de Carvalho AD et al (2017) Coronary irrigation in Puma concolor (Carnivora: Felidae). Int J Morphol 35: 925-930. https://doi.org/10.4067/S0717-95022017000300021

Wilkie LJ, Smith K, Luis Fuentes V (2015) Cardiac pathology findings in 252 cats presented for necropsy; a comparison of cats with unexpected death versus other deaths. J Vet Cardiol 17(Suppl 1):S329 S340. https://doi.org/10.1016/j.jvc.2015.09.006
Yodzis P (2001) Must top predators be culled for the sake of fisheries? Trends Ecol Evol 16:78-84. https://doi.org/10.1016/S01695347(00)02062-0

Publisher's note Springer Nature remains neutral with regard to jurisdictional claims in published maps and institutional affiliations. 